\title{
MANAGEMENT OF PACKAGING LABELING TECHNOLOGY IN THE CONTEXT OF IMPROVING THE FINAL PRODUCT QUALITY AND WORK SAFETY
}

\author{
doi: $10.2478 /$ czoto-2021-0013 \\ Date of submission of the article to the Editor: 12/12/2020 \\ Date of acceptance of the article by the Editor: 31/03/2021
}

\author{
Krzysztof Knop - orcid id: 0000-0003-0842-9584 \\ Czestochowa University of Technology, Poland, krzysztof.knop@wz.pcz.pl
}

\begin{abstract}
High demands on the aesthetics of the final product as well as sophisticated packaging shapes make the labeling process an operation that requires more and more precision and quality of workmanship. The quality of the labeling process is influenced mainly by the technology used, i.e. machinery and equipment, the knowledge, skills, and experience of operators, organization and working methods used, and by aspects related to proper maintenance. This article is a case study on the analysis and evaluation of the technology used in the process of labeling glass packaging and its impact on quality and work safety. The article aims to answer the question: does the labeling machine used by the surveyed company, due to the current portfolio of modernity of its parts and subassemblies, guarantee the realization of the labeling process at a high quality level and work safety. The article discusses in depth the factors influencing the quality of the process of labeling glass packaging in the studied company, paying attention to the issues related to the applied technology. ABC technology method was used to assess technology level and also indirectly safety level and Ishikawa diagram, $\mathrm{L}$ shape matrix diagram and affinity diagram to analyze and improve quality level. The article ends with a list of specific improvement actions to be taken to achieve the ultimate goal of managing the technology of glass packaging labeling - high quality of the final product resulting from the labeling process.
\end{abstract}

Keywords: labeling technology, machine modernity, quality, safety, improvement

\section{INTRODUCTION}

The high demands on the aesthetics of the final product, as well as the sophisticated shapes of the packaging, make the labeling process an operation that requires more and more precision and thus the quality of workmanship (Albert, 2010). Today, the label not only has an informative function but has also become a tool in the hands of marketing (Kula, 2004). The effectiveness of this tool is determined by not only the appropriate graphic design and shape adapted to the selected packaging but also by the durability, accuracy, and aesthetics of the label application (Prinsloo et al., 2012). Labeling is one of the last operations in the packaging process before the shipment of 
products to the customer. The quality of this process will determine whether the product will be appreciated by the customer (Ampuero and Vila, 2006; KlimeckaTatar, 2017; Ulewicz and Novy, 2019). Attractive label, correctly applied with care for high precision and aesthetics can attract the customer's attention and encourage them to buy (Jerzyk, 2014), which is consistent with the A.I.D.A model (Hadiyati, 2016). Carelessly labeled packaging (ex. crooked, dirty label) may discourage the customer from the product itself. Before deciding to buy a product with a label, customers reach for it from the shop shelf, look at it, read the relevant information from the label and if the product convinces them - they put it in the basket and pay for it (Stir, 2018; Blythe, 2008). The process of product labeling and its outcome, its aesthetics is a factor determining consumers' purchasing decisions and influencing on sales volumes (Mumcua and Kimzan, 2015; Bloch et al., 2003). A product may "defend" its quality after it has been purchased, but the customer may not give it such a chance if he finds, through a visual assessment, that the aesthetics of the product itself is far from his expectations (Ulewicz, 2016). This is in line with a well-known saying: "fine feathers make fine birds" - low quality of the labeling process (assessed by an external view of the product) has an impact on the perception of the total quality of the product itself discouraging the customer from buying it (Wyrwa and Barska, 2017).

The factor determining the quality of the labeling process and its result is the technology used. The labeling process due to its automation is realised by labeling machines and devices (Lee et al., 2008). The labeling machine is the main "carrier" of labeling technology. Such factors as age, technical condition, way of cleaning, and maintenance of labeling machine can affect the quality level of the final product and work safety (Ulewicz et al., 2013). The level of machine modernity has an impact on the quality of the realised process/manufactured product (Knop et al., 2008). Technology is often equated with equipment and apparatus or with a collection of installations, machines, and tools capable of carrying out production tasks in a given time (Bullinger, 2009). However, technology is not just about its material element (machines and devices). Technology in a broader approach is (Lowe, 1995) a combination of knowledge, skills, the experience of employees, machines, devices, methods of process implementation as well as production and work organization. All these factors should be taken into account to assess the impact of labeling technology on the quality of this process and work safety level. However, the basic technology elements are people, machines, methods, and management, so factors from the 4M category appearing in the Ishikawa diagram (Coccia, 2017). The quality of the labeling process and work safety level is the result of technology factors influence that need to be identified and analyzed in order to improve the quality of the final product.

The aim of the article is to identify and analyze factors related to labeling technology in the example of a selected food industry company in terms of their impact on the quality of the final product and the level of work safety and to propose improvement actions.

\section{METHODOLOGY}

The research facility is a medium-sized enterprise from the food industry located in the northern part of the Silesian Voivodship and operating in the industry since 1998. The company produces a wide range of food products, among the most important, are: canned vegetables, concentrates, vinegar, spices, dinner accessories, sauces, 
juices, syrups, and fruit preserves. The company currently employs over 200 employees.

The labeling process was analyzed with one of the food products manufactured in the examined company - tomato concentrate packed in glass packaging with a paper label. Paper label is the only type of label used for this type of product. The only technology used to label tomato concentrate products is glass packaging labeling technology using paper labels.

To assess the impact of labeling technology on the quality of the final product and work safety in the surveyed company, the concept of labeling technology was defined paying attention to its basic components $(4 \mathrm{M})$. The result of such analysis is shown in Figure 1.

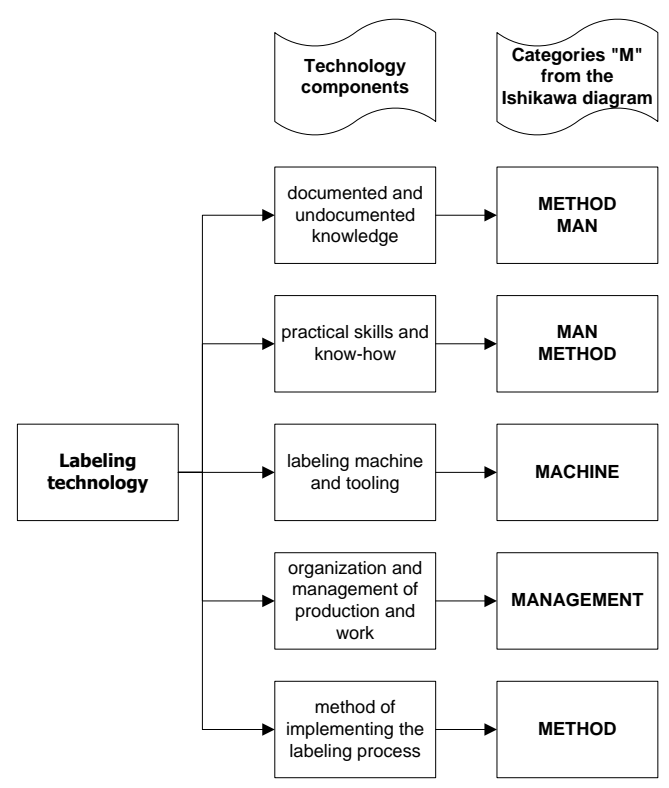

Fig. 1. Components of labeling technology and their reference to the category $4 \mathrm{M}$

The Ishikawa diagram, also known as the cause and effect diagram or fishbone diagram (Coccia, 2017; Siwiec and Pacana, 2021; Siwiec and Pacana, 2019), was used as a tool for the impact of technology elements on the quality of the labeling process and work safety level. The Ishikawa diagram allowed to present the relationship between the problems - the low aesthetics of the product after the labeling process (1) and accidents and near misses (2) (effects) and the factors (causes) causing them from the side of factors of labeling technology. Based on the specifics of the problems and their determinants, the following categories were selected for the analysis: machine, man, method, management (4M) and material, environment $(5 \mathrm{M}+\mathrm{E})$.

The main carrier of the tomato concentrate labeling technology in the studied enterprise is the labeling machine used. The labeling process in the company is carried out by the Alfa Quattro Junior to 200 labeling machine manufactured by an Italian company - ALFA Construzioni Meccaniche. This machine works in line, connected with other devices by belt (plate) conveyors. It receives products from the pasteurization station (pasteurizer), then passes them to the packaging station in shrink film (packing machine). The Alfa Quattro labeling machine is a machine designed for sticking paper labels on cylindrical packaging for label per one packaging 
using starch glue. Sticking can take place on part of the circuit or the entire circumference. The adhesive is applied in strips along the entire length of the label. The working principle of the labeler (ALFA Construzioni Meccaniche, 1988) is based on cyclic pendulum movements through the label holder (1) with the cylinder (2) permanently moistened with adhesive and the dividing screw (3) rotating constantly. The incoming packaging is introduced through the screw (3) into the gluing zone after giving it the right phase and after separating it into the required distances. Within the screw, there is a label switch, which, after detecting the packaging, extends the solenoid lever, which results in the label holder getting closer to the adhesive cylinder (2). The cylinder takes the label and transfers it to the gluing zone. Then the label is transferred from the adhesive cylinder to the roller station (4) and returned to the packaging supplied with a screw (3). Then the packaging (along with the beginning of the label attached) goes to the roller station (5) where it is rolled around its axis. During this movement, the label is pulled out all the way and at the same time pressed against the packaging by a sponge (6). The view of the tested labeling machine together with its most important components is shown in Fig. 2, and the machine safety is regulated in accordance with the rules (Fíla, et al., 2020; Kielesińska, 2020).
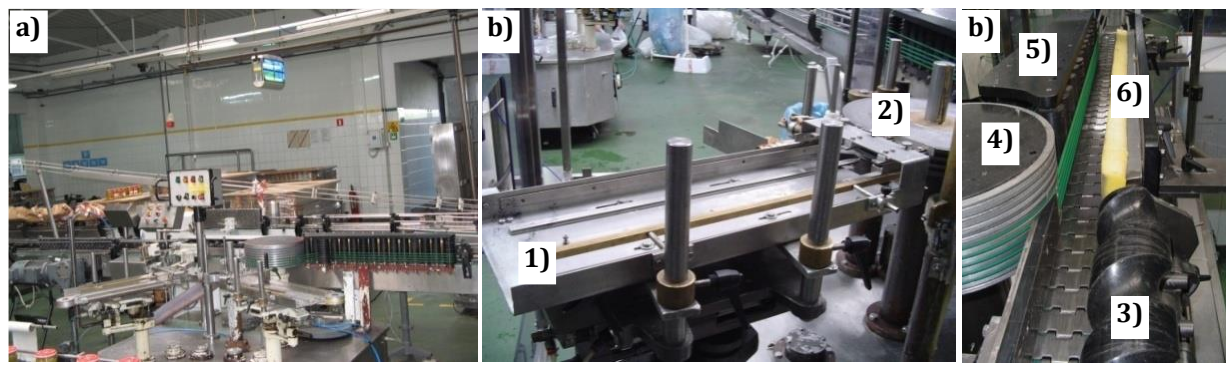

Fig. 2. View of the tested labeling machine (a) and its selected components (b): 1) label feeder, 2) gluing cylinder, 3) dividing screw, 4) roller station, 5) end roller stand, 6) foam pad

It was assessed whether the applied labeling machine due to the current technology portfolio and the level of modernity could ensure the correct quality of gluing labels on jars and work safety. To assess the level of the machine modernity, the ABC technology method and the Parker 5-level scale were used (Stasiak-Betlejewska and Borkowski, 2009). The ABC technology method assumes, before carrying out the assessment, the division of the machine components into 3 categories (marked as $A$, $\mathrm{B}$, and $\mathrm{C}$ ) with a different contribution to the market value of the machine and creating added value for the product. "A" subassemblies are so-called basic subassemblies, which include fundamental machine subassemblies guaranteeing the product special attributes and determining its market value. "B" subassemblies are supportive components, often of a general nature, whose role depends to some extent on the basic subassembly. The users are usually not interested in development of this subassemblies category. They will benefit from their improvements during buying the machine. "C" subassemblies are secondary components, which are mainly technologies that are not subject to the user's innovative activity and are not of great importance when buying a new machine, but they should not be completely ignored, because they determine the safe operation (Ingaldi, 2015). The assessment of the level of the materialized machine technology in the ABC technology method is made by assessing individual machine parts and assemblies (Ingaldi and Dziuba, 2015). 
This assessment is done using a 5-point Parker scale, where the individual levels mean:

- level 1 - simple parts, it is possible to manufacture them using craft techniques, e.g. covers, machine foundation,

- level 2 - parts for the production of which unchanged technologies have been used and known for many years, e.g. standard engine cooling system,

- level 3 - parts manufactured using mastered technology that requires appropriate technical knowledge, e.g. a standard electric motor,

- level 4 - parts that have been manufactured using modern market technologies, e.g. displaying information on the control panel monitor,

- level 5 - parts resulting from the combined use of modern technologies, patented and found only in the machine of a specific company (StasiakBetlejewska and Borkowski, 2009).

The results of the unintentional, non-standard, unfavorable influence of technology elements $(4 \mathrm{M})$ on the labeling process are the internal products nonconformities, complaints, and also accidents at work. It will be assessed by Ishikawa diagram the impact of the technology elements (4M) on the occurrence of product aesthetics nonconformities and accidents at work and near misses, taking into account impact of important non-technological factors such as material and environment. To analyze the relationship between the all analysed elements (technological and non-technological) and product nonconformities and accidents at work, one of the quality tools from the group of so-called "new" (descriptive) will be used - the matrix diagram (Fonseca et al., 2015). The matrix diagram will make it possible to indicate the impact of the category of technology factors on nonconformities and accidents at work occurrence, after taking into account the importance of the nonconformities and accidents under consideration for the customer and company's owner.

A well-defined and analyzed problem is a half-resolved problem. After the identification of the factors affecting the problem of the low quality of the labeling process and work accidents will be done, the identification of the ways of solutions to the problem will be identified and grouped. For this purpose, one of the new quality tools will be used - the affinity diagram (Fonseca et al., 2015; Biały and Hąbek, 2018).

\section{RESULTS AND DISSCUSSION}

\subsection{The level of machine modernity and its impact on the quality of the process} and work safety

The labeling machine subassemblies have been identified based on its operation and maintenance documentation (ALFA Construzioni Meccaniche, 1998) and then classified into categories $A, B$, and $C$ according to the $A B C$ technology method. The percentage result of this classification is shown in Fig. 3.

a)

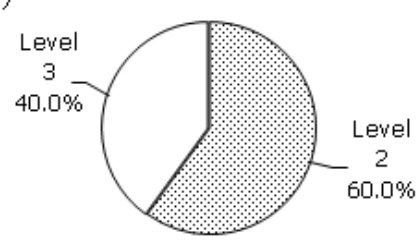

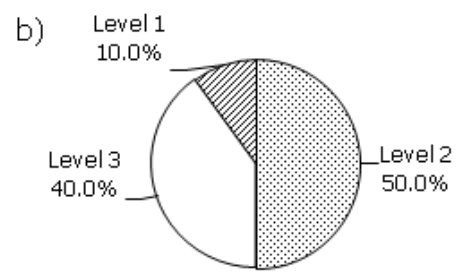

c)

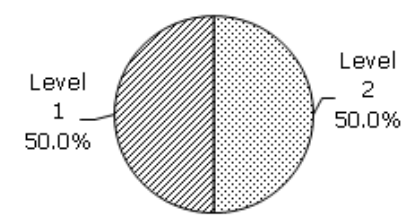

Fig. 3. The structure of modernity of the labeling machine subassemblies: a) basic subassembly "A", b) supporting subassembly "B", c) secondary subassembly "C". 
In the case of the basic subassembly, there are mainly subassemblies at the second level of modernity $(60 \%)$, followed by the third $(40 \%)$. For the supporting subassemblies, $50 \%$ of the subassemblies were rated at the second level of modernity, $40 \%$ at the third. Half of the secondary subassemblies were classified at the first level of modernity, while half at the second level. The Pareto-Lorenz analysis (Pacana and Czerwińska, 2019) for the levels of modernity of all subassemblies of the tested machine allowed obtaining the results, which are shown in Fig. 4.

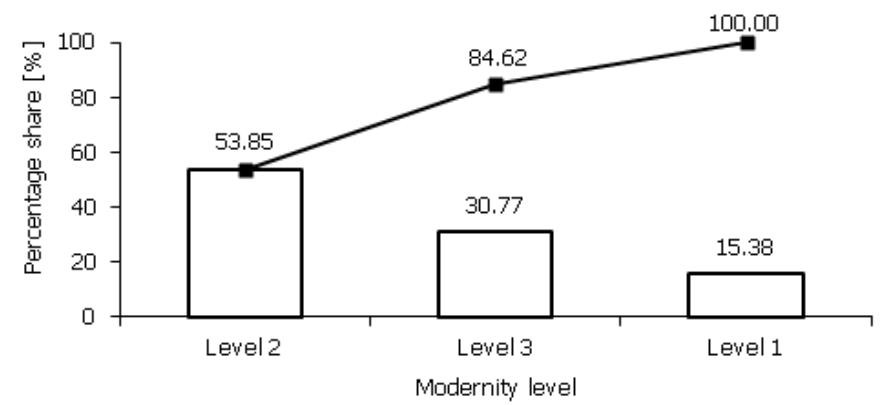

Fig. 4. Pareto-Lorenz diagram for analyzing the share of levels of modernity of labeling machine subassemblies

The modernity of the subassemblies of the labeling machine is between 1 and 3 levels on the Parker scale. The second level is the dominant level of modernity (14 out of 26 all subassemblies), which indicates that the labeling machine cannot be classified as technologically modern machinery. The analysed machine is structurally simple, technically easy to maintain, and repair. The basic subassemblies of the machine involved in the application of labels on jars are made using known technologies, unchanged for many years. They can be produced or reproduced using basic machining processes. Noteworthy is the poor results recorded in the subassemblies responsible for applying the adhesive and applying it to the label before gluing. The technical solutions used in the machine create difficulties with maintaining cleanliness around the machine and have an impact on the aesthetics of the final product and also the level of work safety (possibility of slipping, falling, fractures of limbs, or head injuries). However, it is affected in particular by the technical condition of these components and their proper maintenance. Is the low level of machine modernity the main reason for the poor quality of the labeling process and accidents at work and near misses? The answer to this question is the next section in this article.

\subsection{Analysis of factors on the side of technology affecting the quality of the process and work safety}

It was made the identification of influence the technology \& non-technology factors on low aesthetics of the final product and on accidents at work and near misses. To this end, workshops were organized in the company to which people who could contribute the most in terms of learning about the causes of this problem were invited. Data were also collected on accidents at work and their causes related to the analyzed packaging labeling station. A brainstorming was carried out in which participants were asked what the reasons for the analysed problems are. Participants' answers were 
written on a piece of A0 paper. In the next step, answers were grouped into categories $5 \mathrm{M}+\mathrm{E}$ and presented in the form of the Ishikawa diagrams (Fig. 5).

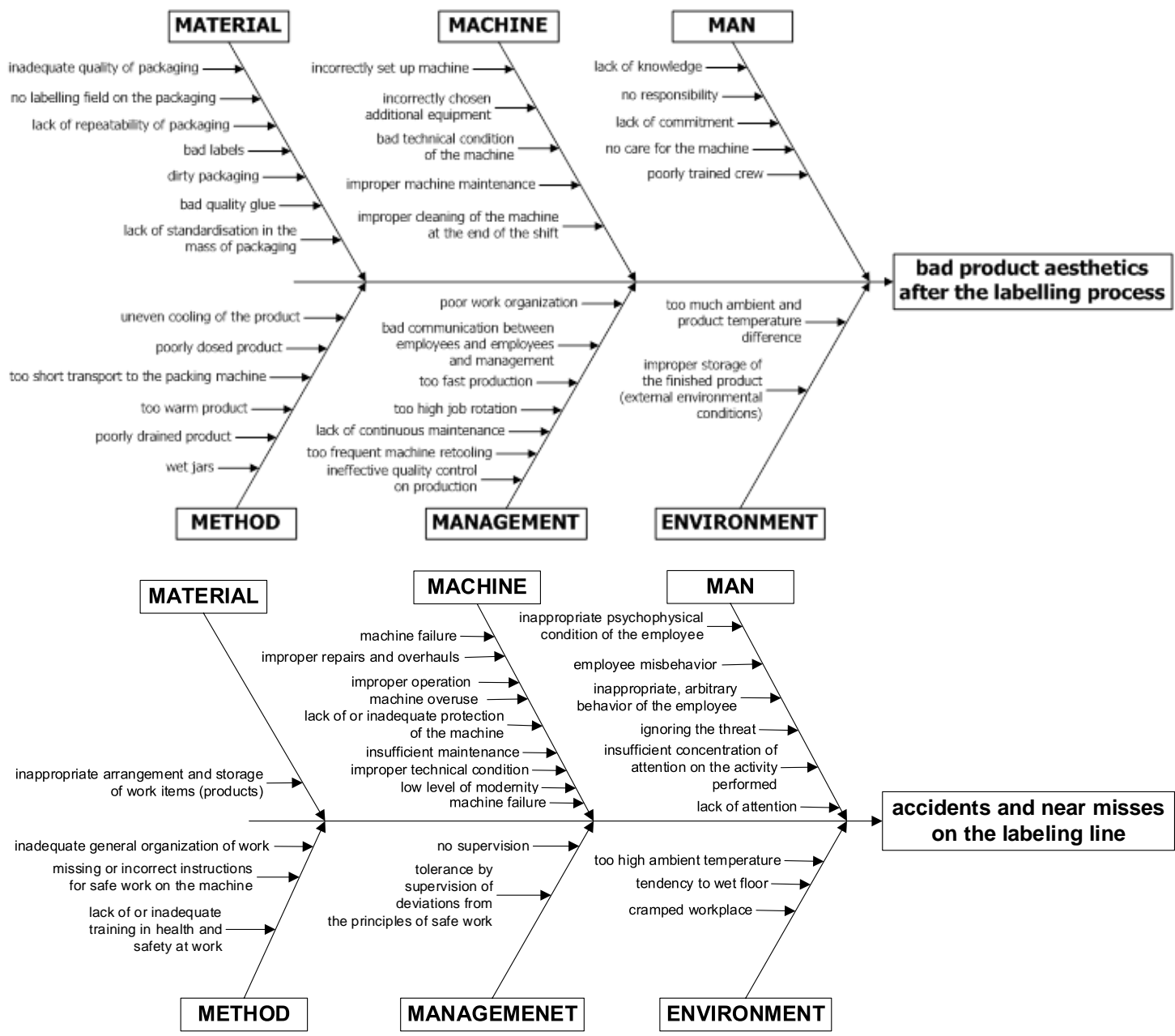

Fig. 5. Ishikawa diagrams for analyzing the causes of low product aesthetics after the labeling process and reason for potential accidents and near misses on the labeling line

The problem related to the low aesthetics of the product is a complex problem, which is influenced by many different factors from the area of $5 M+E$. The analysis of factors from the Ishikawa diagram shows that in the "machine" area, experts noticed problems related to its improper technical condition, improper maintenance, servicing and cleaning, wrong choice of accessories, wrong machine positioning. "Man" is also the cause of poor quality labeling, in particular his lack of knowledge on how to care for the machine, his lack of responsibility, commitment, poor training. Problem issues also appeared on the side of "methods" of work and production. Inadequately cooled product, poorly dosed, too warm, too wet, too short section of conveyor between pasteurizer and labeling machine are problems that require solutions. "Managing" the production process and machine maintenance is also an area for improvement. Poor work organization, communication between employees, too fast production, frequent retooling due to frequent changes in production plans, high rotation of employees in workstations, lack of continuous maintenance, inefficient quality control require an effective solution. What enters the process must also be good, in the sense of starting "materials" (glue, jars, and labels). There were also irregularities in this area. Improper 
storage of finished products (bad ambient conditions, temperature), i.e. the "environment" area, can also cause nonconformities.

As can be seen from the analysis, accidents at work or near misses are mainly caused by elements related to technology, i.e. machine, human, method (work organization), and management. Man and machine are the factors that determine the most possibility of an accident at work (the largest number of causal factors). Inappropriate behavior of an employee in the workplace, non-compliance with health and safety rules, ignoring the risk are just some of the factors that may cause accidents at the labeling station caused by the human factor. The poor technical condition of the machine, lack of care for regular maintenance and cleaning of the machine, the order in the workplace, low level of modernity of the machine causing problems with maintaining the technological regime, low level of machine protection are factors that are important in the "machine" category.

The problems being investigated are complex problems. To solve them, it cannot be acted in one direction, paying attention only to one of the categories of problem factors. First, these activities should be targeted, oriented in critical areas. Which category of technology factors is critical? From which category it should be started improving the process of labeling. The answer to this question is in the next section of the article.

\subsection{Analysis of the relationship between the nonconformities types and accidents and near misses vs. technology factors}

The relationship between the nonconformities of the product and accidents and near misses (one side) and the categories of factors causing them has been analysed (second side) - technology (4M) and non-technology (rest). The result of such an analysis is presented in the form of a matrix diagram (Knop, 2016) in Table 2. Using a scale of $1-5$, the importance of nonconformity for the customer and also the importance of accidents and near misses (generally) for the owner of the company. Based on the strength of the relationship a ranking of factor categories (6M) was developed for improvement purposes (Rosak-Szyrocka and Knop, 2018).

Table 2

Matrix diagram for the analysis of the impact of technology and non-technology categories factors on nonconformities related to the aesthetics of the product labeling process and on accidents and near misses

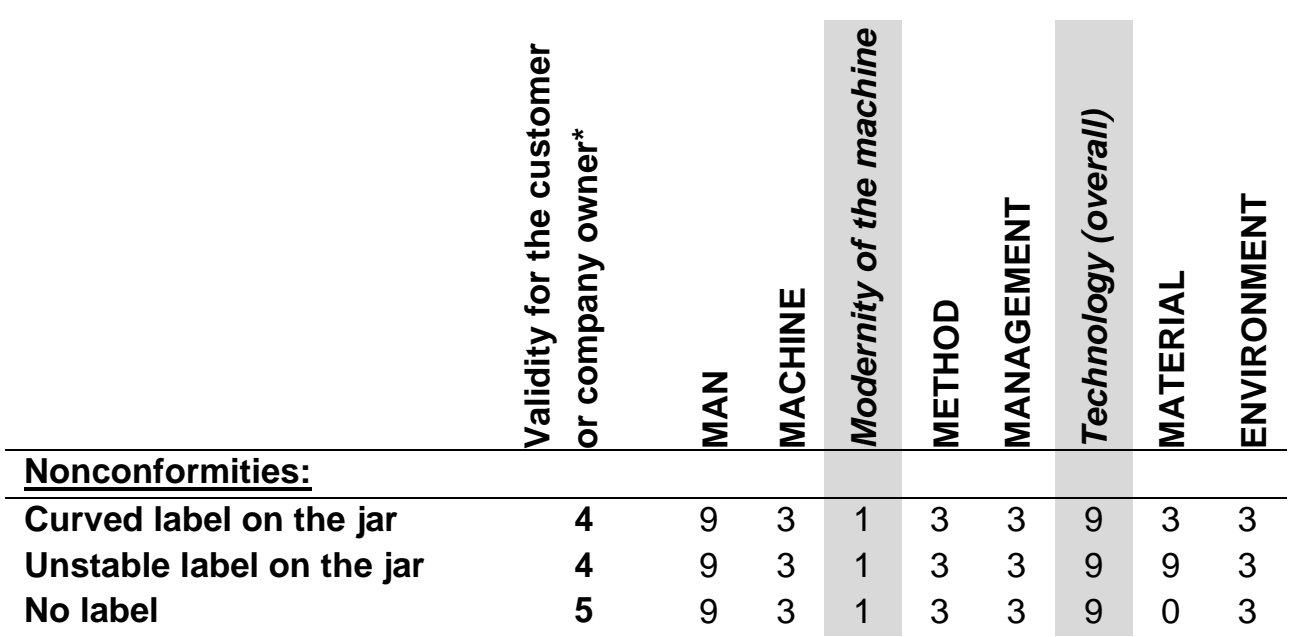




\begin{tabular}{|c|c|c|c|c|c|c|c|c|c|}
\hline 2 labels on 1 jar & 4 & 9 & 3 & 1 & 3 & 3 & 9 & 0 & 0 \\
\hline Dirty / illegible label & 5 & 9 & 3 & 1 & 3 & 3 & 9 & 9 & 1 \\
\hline Damaged label & 5 & 9 & 9 & 3 & 3 & 1 & 9 & 3 & 1 \\
\hline The sum of the products: & & 243 & 111 & 37 & 81 & 71 & 243 & 108 & 49 \\
\hline Ranking: & & $\mathrm{I}$ & II & $\mathrm{n} / \mathrm{a}$ & IV & $\mathrm{V}$ & $\mathrm{n} / \mathrm{a}$ & III & $\mathrm{VI}$ \\
\hline $\begin{array}{l}\text { Accidents and near } \\
\text { misses: }\end{array}$ & $5^{\star}$ & 9 & 3 & 1 & 9 & 1 & 9 & 1 & 1 \\
\hline The sum of the products: & & 45 & 15 & 5 & 45 & 5 & 45 & 5 & 5 \\
\hline Ranking: & & $\mathrm{I}$ & II & $\mathrm{n} / \mathrm{a}$ & $\mathrm{I}$ & III & $\mathrm{n} / \mathrm{a}$ & III & III \\
\hline
\end{tabular}

The analysis shows that "man", as a component of the labeling technology, is the primary source (cause) of the nonconformities related to the aesthetics of the product and also accidents and near misses. His knowledge, skills, experience, and commitment to work influence the number of nonconformities appearing in the labeling process. Compliance with health and safety rules, not ignoring threats in the workplace, proper behavior, concentration on the activities performed, and proper psychophysical conditions are the factors that determine accidents and potentially accidental events in the examined workplace.

The machine, and in particular its technical condition is a factor determining the creation of non-conforming products and work accidents. As a separate category, the machine's modernity has been distinguished and analyzed. As the analysis have shown, the low level of machine modernity is not an important reason causing the product nonconformities and also low work safety level. The machine was designed to work properly without arising any nonconformities and to work safety. Due to the construction, the base of operation, the technological advancement, however, it is not a completely fault-proof machine, insensitive to any non-standard situations that may arise during its operation, and $100 \%$ error/mistake-proof in range of safety (low level of parts modernity in secondary subassembly "C"). But, what should be underlined, the analysed labeling machine if will be properly maintained (maintenance, cleaning, repairs, inspections), in good technical condition (as results of these activities), properly operated (training, manuals, control), working in proper environmental conditions (humidity, temperature), on high quality materials (glue, label, jar) can produce good products regardless of the level of modernity and also reduce risk of work accidence appearing.

The area of organization and management, as well as production and work methods, is, as it turned out, an important determinant of product nonconformities and a very important reason for work accidents. Lack of system solutions in the field of maintenance, production planning forcing often change production plans and changeover, the high pace of production, ineffective quality control based only on human senses, poor communication between various divisions of the organization about current problems (production/quality/safety) are problematic themes that must be solved to facilitate the machine's work at a high quality and safety level. The analyzes show that technology has a very strong impact on the quality and safety of the labeling process. What improvement actions should be taken to limit product nonconformities and increase safety level? Proposals for such actions are presented in the last part of the article. 


\subsection{Proposals for actions to improve labeling technology management in the context of increasing quality and work safety}

Labeling technology as a combination of man, machine, methods, and management is a factor determining the quality and work safety problems related. In response to the potential to improve, the countermeasures were identified, which are summarized in Table 3.

Table 3

Relationship diagram for grouping remedial actions to improve quality $(Q)$ and safety $(S)$ level

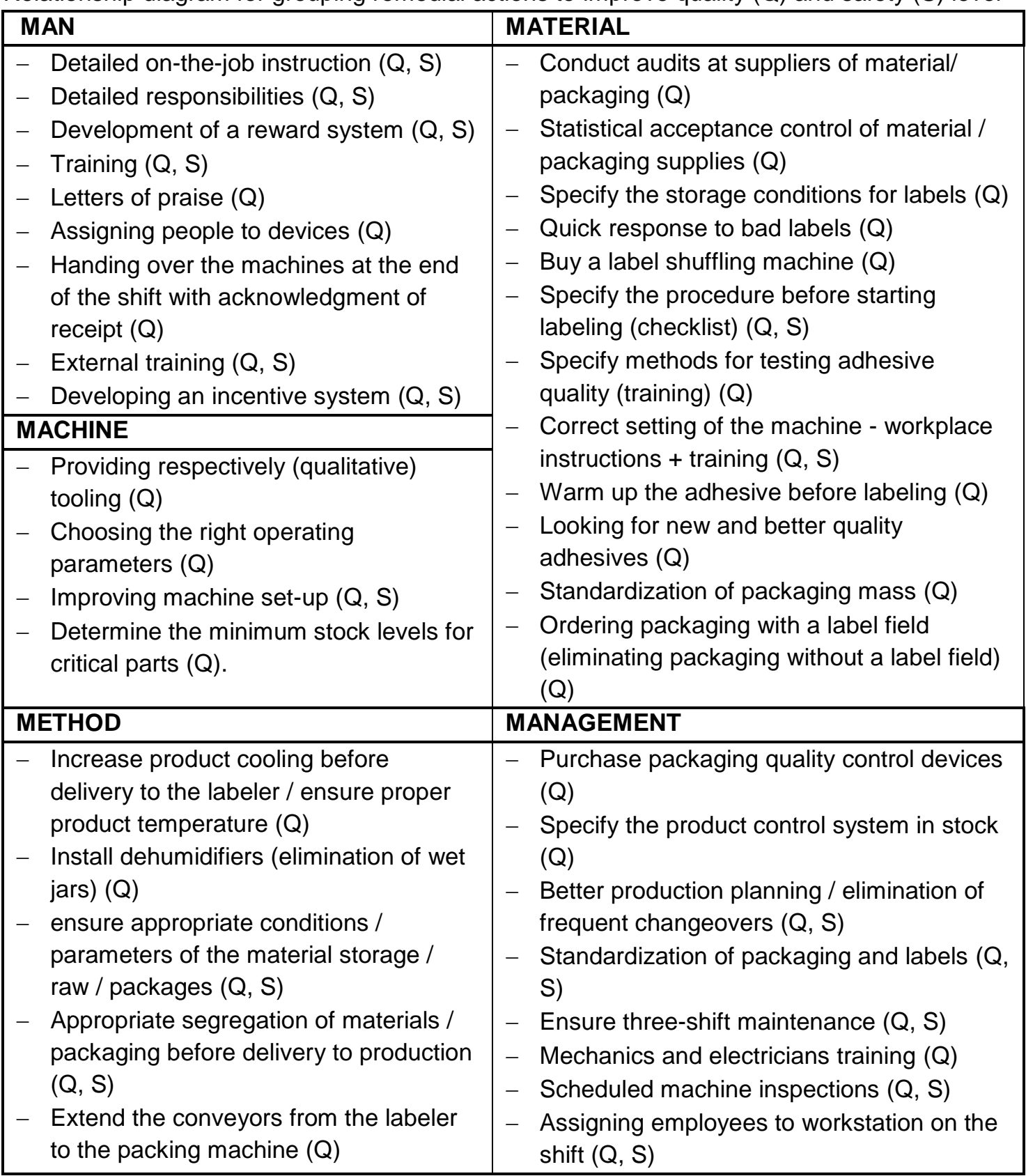

In order to improve the quality of the product and work safety, it is necessary to start from the key component of technology - man. Actions are needed to increase the knowledge, responsibility of employees, their involvement, and motivation in work, which requires systemic solutions. Employees who are properly motivated and rewarded will certainly work more efficiently, scrupulously, and also safety. This 
applies to machine operators as well as maintenance department workers. Secondly, the focus should be on the machine and work method: organize the right tooling, ensure the correct working parameters, improve the machine setting by preparing the appropriate visual instructions, and determine the minimum inventory for critical parts of the machine. Thirdly, it is important to ensure the quality of the materials supplied, i.e. jars, labels, and glue. In the case of packaging, first of all, their shape and quality are important, as well as repeatability of dimensions and appropriate rigidity. In relation to labels, the stability of dimensions, the quality of their printout, the manner and storage conditions as well as the skillful "handling" before placing them in the label feeder of the labeling machine are important. The quality of the adhesive used, its type, brand, technological parameters (e.g. drying time), and the method of its preparation affect the label labeling durability. Better, more selected material suppliers and appropriate system solutions (method and management area) are needed.

\section{CONCLUSIONS}

The management of labeling technology is a process that requires skillful coordination of technology and non-technology related factors to achieve the objectives of quantity, quality, safety, cost, and in the end obtaining customer satisfaction and competitive advantage. The correct technology management and its factors $(5 \mathrm{M})$ is needed to achieve goals in quality and safety. In the article was proven that basic technology factors influence the quality of the labeling process and work safety in different ways. The article was identified and analyzed the factors of labeling technology affecting quality problems related to its aesthetics. Categories factors relevant to the labeling technology were identified, also the impact of these categories factors (and technology itself) on quality problems (nonconformities) and accidents \& near misses. Improvement actions were proposed, which will contribute to improving the quality and safety level on the labeling station.

The results underlined that the analysed labeling machine is not modern, but a low machine modernity level influences in a slightly way the quality of the labeling process and safety level. It was emphasised that although the analysed machine is not modern, it could ensure work at the appropriate quality and work safety level, but it is necessary to ensure its proper working conditions. Man and method are key elements in the field of labeling technology management in the studied enterprise for achieving quality and work safety objectives. The man and work method turned out to be the main causes of quality and work safety-related problems. A properly set, maintained, cleaned machine with a good technical condition will be able to properly carry out the labeling operation. Actions are needed to improve these key technology areas. It has been shown that these activities should be aimed at improving the knowledge, skills of employees, their approach to work, motivation, and increased responsibility. Even the latest technology, if not properly maintained, can create quality and safety problems, and vice versa, older technology, whit proper take care of it, should performing tasks of a high quality and safety level. To increase the current labeling technology level investments in a new machine with a newer technology portfolio are necessary, which is expensive action and in this particular case unjustified. It is enough to take appropriate improvement actions in the area of technology to achieve satisfactory results in the area of quality and work safety. Properly managed labeling technology 
focused on the human factor and work methods should bring the expected quality and work safety effects to the company.

\section{REFERENCES}

Albert J., 2010. Innovations in food labeling, The Food and Agriculture Organization of the United Nations and Woodhead Publishing Limited, Sawston, Cambridge.

ALFA Construzioni Meccaniche, 1988. Operation and maintenance manual for the labeling machine AlfaQuattro, Parma.

Ampuero O., Vila N., 2006. Consumer perceptions of product packaging, Journal of Consumer Marketing, 23, 2, 102-114.

Biały W., Hąbek P., 2018. Quality engineering tools in analysis of failure of longwall mining complex, Mining - Informatics, Automation and Electrical Engineering, 3, 535.

Bloch P. H., Brunel F. F., Arnold T. J., 2003. Individual differences in the centrality of visual product aesthetics: Concept and measurement, Journal of Consumer Research, 29, 4, 551-565.

Blythe J., 2008. Consumer behavior, London. Thomson.

Bullinger H.-J., (Ed.), 2009. Technology Guide. Principles - Applications - Trends, Springer - Verlag Berlin Heidelberg.

Coccia M., 2017. The Fishbone diagram to identify, systematize and analyze the sources of general purpose technologies, Journal of Social and Administrative Sciences, 4, 4, 291-303.

Fíla O., Sellner K., Vysloužilová D., Klimecka-Tatar D., 2020. Safety and Automatization of Machining Line. System Safety: Human - Technical Facility Environment, 2(1), 268-274, DOI: 10.2478/czoto-2020-0033

Fonseca L., Lima V., Silva M., 2015. Utilization of quality tools: does sector and size matter? International Journal for Quality Research, 9, 4, 605-620.

Hadiyati E., 2016. Study of marketing mix and AIDA model to purchasing on line product in Indonesia, British Journal of Marketing Studies, 4, 7, 49-62.

Ingaldi M., Dziuba Sz., 2015. Modernity Evaluation of the Machines Used During Production Process of Metal Products, 24th International Conference on Metallurgy and Materials (METAL 2015), Brno, Czech Republic, 1908-1914.

Ingaldi M., 2015. Evaluation of Modernity Level of Production Equipment in the Steel Industry Company, Hutnik-Wiadomości Hutnicze, 81, 11, 793-797.

Jerzyk E., 2014. Packaging design and its components in purchase decision-making process, Journal of Marketing and Market Studies, 4, 391-398 (in Polish).

Kielesińska A., 2020. Safety of Imported Machines - Selected Issues in the Context of Polish (UE) Regulation. System Safety: Human - Technical Facility - Environment, 2(1), 174-182. https://doi.org/10.2478/czoto-2020-0021

Klimecka-Tatar D., 2017. Value stream mapping as lean production tool to improve the production process organization - case study in packaging manufacturing. Production Engineering Archives, 17, 40-44, DOI: 10.30657/pea.2017.17.09

Knop K., Borkowski S., Stachurski S., 2008. Modernity of Filling Machine in the Aspect of the Exact Packing, In: Quality Improvement and Machines Exploitation, S. Borkowski, Kliber J. (Eds.), Publishing and Press Association of Universities Russia, Saint-Petersburg, 63-68.

Knop K., 2016. Using a QFD Method and CTQ Tree to Identify the Areas Needing Improvement in the Product - Farm Truck Trailer, Scientific Papers of Silesian 
University of Technology. Organization and Management Series, 1947, 87, 219236.

Kula P., 2004. Packaging labeling in the production process, Weighing, dosing, packaging, 2, 4-5 (in Polish).

Lee S., Yam K. L., Piergiovanni L., 2008. Food packaging science and technology. CRC Press, London.

Lowe H., 1995. Management of Technology. Perception and opportunities, Springer Netherlands.

Mumcua Y., Kimzan H. S., 2015. The Effect of Visual Product Aesthetics on Consumers' Price Sensitivity, Procedia Economics and Finance, 26, 528- 534.

Pacana A., Czerwińska K., 2019. Analysis of the causes of control panel inconsistencies in the gravitational casting process by means of quality management instruments, Production Engineering Archives, 25, 12-16.

Prinsloo N., van der Merwe D., Bosman M., Erasmus A., 2012. A critical review of the significance of food labelling during consumer decision making, Journal of Family Ecology and Consumer Sciences, 40, 83-98.

Rosak-Szyrocka J., Knop K., 2018. Quality Improvement in the Production Company, MAPE 2018, 1, 1, 521-527.

Siwiec D., Pacana A., 2019. The use of quality management techniques to analyse the cluster of porosities on the turbine outlet nozzle, Production Engineering Archives 24, 33-36.

Siwiec D., Pacana A., 2021. Method of improve the level of product quality. Production Engineering Archives, 27(1), 1-7, DOI: 10.30657/pea.2021.27.1

Stasiak-Betlejewska R., Borkowski S., 2009. Assessment of the CNC Machine Modernity Basing on the ABC Technology Method. TRANSCOM. 8th European Conference of Young Research and Scientific Workers. Proceedings. Section 2. Economics and Management, 19-22.

Stir M., 2018. Product Quality Evaluation in Physical Stores versus Online Stores, Expert Journal of Marketing, 6, 1, 7-13.

Ulewicz R., Novy F., 2019. Quality Management Systems in Special Processes, Transportation Research Procedia, 40, 113-118.

Ulewicz R., 2016. Quality Management System operation in the woodworking industry. Int. Conf. Path Forward for wood products: a global perspective. Proc. of Sci. Papers, Zagreb, WOODEMA, 51-56.

Ulewicz R., Selejdak J., Borkowski S., Jagusiak-Kocik M., 2013. Process management in the cast iron foundry. Metal 2013. Proc. 22nd Int. Conf. Metallurgy and Materials, Ostrava, Tanger, 1926-1931.

Wyrwa J., Barska A., 2017. Packaging as a Source of Information about Food Products, Procedia Engineering, 182, 770-779. 